\title{
Um olhar sobre as questões étnicas-raciais nas enunciações sobre a história da Matemática apresentadas pelos livros didáticos de Matemática do Ensino Médio aprovados pelo PNLD 2018
}

A look at the ethnic-racial issues in the Math history presentations presented by the 2018 PNLD medical education Mathematical books

\author{
Alan Pereira Manoel \\ Camila Aparecida Lopes Coradetti Manoel
}

\begin{abstract}
Resumo: O presente texto é constituído de estudos realizados no Programa de Pós-Graduação em Educação Matemática da Universidade Federal de Mato Grosso do Sul (PPGEdumat/UFMS) e se inscreve na linha de pesquisa "Currículo e Educação Matemática". O objetivo deste artigo é descrever e analisar discursos mobilizados na abordagem feita, acerca da História dos Conjuntos, contidas nos livros didáticos do Ensino Médio, aprovados no PLND 2018. Para alcançar esse objetivo foram utilizadas as contribuições teóricas da análise do discurso na perspectiva foucaultiana e as contribuições de cultura, identidade e representação de Stuart Hall. Nas análises foram observados um currículo de Matemática, enquanto campo político, que, ao apresentar determinadas representações sobre a história da Matemática, provoca o apagamento de questões étnicos-raciais, principalmente aquelas relacionadas à cultura popular negra, por meio de uma hegemonização da cultura ocidental, a partir de seus feitos históricos, em contexto científicos e áreas afins.
\end{abstract}

Palavras-chave: Educação Matemática. Currículo. Análise do discurso. Cultura. Representação.

Abstract: This text consists of studies carried out in the Graduate Program in Mathematical Education of the Federal University of Mato Grosso do Sul (PPGEdumat / UFMS) and is part of the research line "Curriculum and Mathematical Education". The aim of this article is to describe and analyze discourses mobilized in the approach made, about the History of the Sets, contained in the High School textbooks, approved in PLND 2018. To achieve this objective, the theoretical contributions of discourse analysis were used from the Foucaultian perspective and the contributions of culture, identity and representation of Stuart Hall. In the analyzes, a mathematics

Alan Pereira Manoel Mestre em Educação Matemática pela Universidade Federal de Mato Grosso do Sul (UFMS). Professor da Secretaria Municipal de Educação de Campo Grande (SEMED). Mato Grosso do Sul, Brasil. $\square$ alanpmanoel@hotmail.com

Camila Aparecida Lopes Coradetti Manoel Doutoranda Educação Matemática pela Universidade Federal de Mato Grosso do Sul (UFMS). Mato Grosso do Sul, Brasil. $₫$ camilacoradetti@gmail.com

Recebido em 19/07/2019 Aceito em 22/08/2019 Publicado em 01/09/2019 curriculum was observed as a political field, which, by presenting certain representations about the history of mathematics, causes the erasure of ethnic-racial issues, especially those related to black popular culture, through a hegemonization of western culture, from their historical achievements, in scientific context and related fields.

Keywords: Mathematical education. Curriculum. Speech analysis. Culture. Representation. 


\section{Introdução}

O presente texto se constitui pelos estudos que vimos realizando no Programa de PósGraduação em Educação Matemática da Universidade Federal de Mato Grosso do Sul (PPGEdumat/UFMS).

Durante a fase final da escrita da dissertação do primeiro autor, intitulada "Aspectos históricos do estudo do Cálculo Diferencial e Integral no ensino secundário brasileiro entre 1889 e 1929" (MANOEL, 2018), foi possível observar a força política da Matemática no mundo e, em especial, no Brasil, durante os anos de 1889 a 1929. Um exemplo dessa força, valorizada, entre outras coisas, pelo pensamento positivista da época, pode ser observada a seguir:

[...] antigamente, todos os governantes tinham, ou antes, estavam ao par do saber de seu tempo, e só com a necessidade do estabelecimento de novas ciências - o que fez a especialização dos conhecimentos- deixaram tão salutar regra. Hoje, porém, graças ao sobre-humano cérebro de Comte - o maior, talvez, depois de Aristóteles - o saber volta à unidade útil e moral dos outros tempos. A síntese foi feita e os estadistas verdadeiramente dignos, servidores práticos da Humanidade, poderão encontrar nela um seguro farol para guiá-los. (VALENTE, 2003, p. 230).

A citação anterior corresponde a um jovem da década final do século XIX e era destinada aos deputados, instalados na Câmara - "esse viveiro de bacharéis ignorantes que não sabem Matemática" (BARRETO, 1990, p. 67-69, apud VALENTE, 2003, p. 231). Ao proferir tais palavras, o jovem fez uma crítica a alguns governantes da época, colocando como ponto central de sua crítica a falta de conhecimento matemático desses políticos. Ou seja, a fala pode ser vista como uma evidência de como a Matemática era tratada com importância durante os anos iniciais da fase que ficou popularmente conhecida como Primeira República.

Outro ponto observado, foram alguns indícios de preconceitos que associavam raça e Matemática, como, por exemplo, na fala a seguir do professor Raja Gabaglia:

[...] calculavam o valor numérico de expressões como "a divisão da raiz sétima de três décimos, dividida pela raiz quinta de um meio...". Observando os alunos, ante as dificuldades que encontravam nos exercícios, o professor dissertava e tentava convencer o inspetor que isso não era algo próprio somente de seus discípulos, era da raça, da raça latina: "Têm mais aptidão para o raciocínio indutivo do que para 0 dedutivo" dizia em alto e bom som, com seu sotaque italiano inconfundível (VALENTE, 2003, p. 231).

A fala anterior foi datada como sendo do ano de 1906, ou seja, tal fala foi proferida em um momento histórico, quando o Brasil vivia seus primeiros anos de abolição da escravatura. Isso nos 
levou a pensar sobre uma possível relação entre a força política da Matemática e o preconceito com a raça negra, ou melhor, como a Matemática como um campo político poderia estabelecer laços com uma possível exclusão do povo negro.

Após a defesa da dissertação do primeiro autor, o mesmo iniciou seus estudos no grupo de pesquisa Currículo e Educação Matemática (GPCEM). Munidos pelas afetações citadas anteriormente e por outras ocasionadas diante às discussões do GPCEM, nos voltamos para o livro didático com um olhar acerca de como algumas questões étnicas-raciais são abordadas no currículo de Matemática, e, assim, desenvolvemos o seguinte objetivo para este artigo: descrever e analisar discursos mobilizados na abordagem feita acerca da História dos Conjuntos contidas nos livros didáticos do Ensino Médio aprovados no PLND 2018 (BRASIL, 2017). Por meio deste objetivo, buscamos problematizar a História dos Conjuntos questionando como tal História aborda a presença da cultura popular negra.

Não é de hoje que o GPCEM utiliza o livro didático como material de análise para as suas pesquisas. Em seus últimos trabalhos, o GPCEM buscou uma consonância com o pensamento contemporâneo possibilitando que os pesquisadores pudessem "desconstruir visões enraizadas e naturalizadas" (CORADETTI e SILVA, 2018, p. 3) direcionadas pelos livros didáticos de Matemática. Diante disso, acreditamos na possibilidade de encontrar na História dos Conjuntos apresentada nas obras aprovadas no PLND 2018 (BRASIL, 2017), verdades que podem ser descontruídas.

\section{Construção teórica-metodológica}

Anteriormente, junto ao objetivo desse artigo, mencionamos o conceito de cultura popular negra, neste momento buscaremos explorar um pouco mais este conceito. Para sermos mais específicos, buscaremos estabelecer suas relações com o conceito de discurso e a visão de currículo na contemporaneidade.

De acordo com Hall (2003) temos o seguinte a respeito da cultura popular negra:

por definição, a cultura popular negra é um espaço contraditório. É um local de contestação estratégica. Mas ela nunca pode ser simplificada ou explicada nos termos das simples oposições binárias habitualmente usadas para mapeá-la: alto ou baixo, resistência versus cooptação, autêntico versus inautêntico, experiencial versus formal, oposição versus homogeneização. Sempre existem posições a serem conquistadas na cultura popular, mas nenhuma luta consegue capturar a própria cultura popular para o nosso lado ou o deles (HALL, 2003, p. 341-342). 
Estamos entendendo a cultura popular negra como um espaço importante de luta contra hierarquizações e favorável para o processo de desconstrução, mas que pode perder o seu valor caso seja interpretada por um viés essencialista.

O fato de não pensar a cultura popular negra como essencialista não quer dizer que estamos refutando a existência de "[...] um conjunto de experiências negras historicamente distintas que contribuem para repertórios alternativos [...] mas é para a diversidade e não para a homogeneidade da experiência negra que devemos dirigir integralmente a nossa atenção criativa agora" (HALL, 2003, p. 346). Ou seja, é pensar essa diferença não para homogeneizar, mas como "elementos de um discurso que é diferente - outras formas de vida, outras tradições de representação" (HALL, 2003, p. 346).

O conceito de representação, citado anteriormente, foi definido por Hall $(2016$, p. 31) da seguinte forma: "representação significa utilizar a linguagem para, inteligivelmente, expressar algo sobre mundo ou representá-los a outras pessoas". Ainda baseados nas ideias de Hall (2016), podemos pensar no conceito de representação aliados, entre outras coisas, à produção de conhecimentos. Vale ressaltar que esse conhecimento não se limita à máxima do saber científico, mas ao saber de se posicionar e atuar nos diferentes espaços do tecido social, que consequentemente geram determinadas relações de poder (FOUCAULT, 1987).

Estamos entendendo que as relações entre diferença, conhecimento e relações de poder, também pode ser dada no campo pedagógico ou, mais especificamente, na área de estudos de currículo, pois de acordo com Silva (2015, p. 124), "[...] uma perspectiva pós-estruturalista tentaria desconstruir os inúmeros binarismos de que é feito o conhecimento que constitui o currículo: masculino/feminino; heterossexual/ homossexual; branco/negro; científico/ não científico".

Como já citado, a desconstrução dos binarismos sob os quais buscam compor o currículo é, também, umas das lutas travadas pela cultura popular negra. Isso contribui para que possamos pensar na junção entre cultura popular negra e currículo. Outro ponto de convergência entre cultura popular negra e a área de estudo dos currículos é em relação a forma como as duas áreas lutam contra esses binarismos, ou seja, as duas não entendem que as diferenças particulares se constituam inteiramente; não se trata de uma luta isolada entre grupos e sim que

esses antagonismos se recusam a ser alinhados; simplesmente não se reduzem um ao outro, se recusam a se aglutinar em torno de um eixo único conjunto de oposições que nos situe sempre na mesma relação com os outros, mas com uma série de posições diferentes. Estamos constantemente em negociação, não com um único 
conjunto de oposições que nos situe sempre na mesma relação com os outros, mas com uma série de posições diferentes. Cada uma delas tem para nós o seu ponto de profunda identificação subjetiva. Essa é a questão mais difícil da proliferação no campo das identidades e antagonismo: elas frequentemente se deslocam entre si. (HALL, 2003, p. 346).

Nesse sentido, o currículo e a cultura popular negra são atravessadas por tantas outras subjetividades e todas elas devem ser contempladas em nossa luta, pois, caso isso não seja feito, poderemos estar incorrendo, visto por outra ótica, em erros ou estruturações que não gostaríamos que houvessem.

Para que possamos questionar esses binarismos, antes devemos entender como são dadas as construções dos mesmos. Para Hall (2003, p. 346), "é somente pelo modo no qual representamos e imaginamos a nós mesmos que chegamos a saber como nos constituímos e quem somos. Não há como escapar de políticas de representação". Como é possível notar, Hall (2003) posicionou a ideia de representação como um dos pontos principais na cultura popular negra. Esse autor buscou deslocar o conceito de discurso dado por Foucault para tratar da ideia de representação; sendo assim, para nós também é importante usar tal conceito em nosso trabalho.

Antes de comentar a respeito do que estamos entendendo sobre discurso, gostaríamos de apontar algumas possíveis relações entre as concepções e discurso e as ideias de currículo. Para Lopes e Macedo (2011, p. 41), "currículo é, ele mesmo, uma prática discursiva. Isso significa que ele é uma prática de poder, mas também uma prática de significação, de atribuição de sentido". Ao adotar essa ideia, podemos pensar acerca de como o currículo de Matemática representa a cultura popular negra, ou seja, quais sentidos são atribuídos à cultura popular negra por meio do currículo e como isso pode ser dado enquanto prática discursiva.

Para Foucault (1987), o conceito de discurso deve ser tratado "como práticas que formam sistematicamente os objetos de que falam" (p. 55). Nesse sentido, podemos notar que o discurso possibilita a criação de verdades acerca de determinados objetos; é por meio do discurso que 0 certo e, consequentemente, o errado sobre determinado assunto são criados.

Assim, analisar discursos seria descrever os regimes de verdades para assim expor essa multiplicidade, estaria direcionada para a descrição dos "ditos que se cristalizam" (FISCHER, 2012, p. 103) - como constitutivos da realidade e produtores, como o poder, de inúmeros saberes. Os discursos que mencionamos estariam presentes nos "fatos e coisas ditas não naturais". 
No entendimento de Foucault (1987, p. 135), o discurso é um "conjunto de enunciados, na medida em que se apoiem na mesma formação discursiva". Na concepção de Fischer (2012), inspirada em Foucault, o enunciado

\begin{abstract}
se encontra na transversalidade de frases, proposições e atos de linguagem: ele é "sempre um acontecimento, que nem a língua nem o sentido podem esgotar inteiramente" (Foucault,1987, p.32); trata-se de uma função que cruza um domínio de estruturas e de unidades possíveis e que faz com que (estas) apareçam, como conteúdos concretos, no tempo e no espaço. (FISCHER, 2012, p. 77).
\end{abstract}

Os enunciados são formados pelas enunciações e sobre essas, Foucault (1987, p. 114) menciona que "há enunciação cada vez que um conjunto de signos for emitido. Cada uma dessas articulações tem sua individualidade espaço-temporal". Em outro momento, o autor aponta que a "enunciação é um acontecimento que não se repete; tem uma singularidade situada e datada que não se pode reduzir" (FOUCAULT, 1987, p. 114). Sendo assim, direcionamos nossa atenção não apenas para as "frases", mas também para as imagens, na disposição das figuras nas páginas, nas sessões em que se encontram as informações.

Dessa maneira, adotar a análise discursiva do currículo de Matemática para questionar a posição da cultura popular negra durante a apresentação da História dos Conjuntos dadas pelos livros didáticos aprovados pelo PNLD 2018 (BRASIL, 2017) está associado ao fato de questionar quais verdades estão sendo construídas discursivamente nos livros didáticos e como tais construções posicionam a cultura popular negra.

\title{
3 Procedimentos metodológicos e analíticos
}

Para que pudéssemos dar início ao nosso trabalho, buscamos voltar nossos olhares para os oito livros do primeiro ano do Ensino Médio, aprovados pelo PNLD 2018 (BRASIL, 2017). Já nos capítulos iniciais desses livros, em que foram abordados os conteúdos de conjuntos, foi possível encontrar, por meio da abordagem histórica utilizada para a apresentação do conteúdo, algumas verdades enraizadas, construídas discursivamente e, por isso, passíveis das problematizações.

Durante a introdução deste trabalho apresentamos duas enunciações acerca do que estamos entendemos ser uma valorização da Matemática, durante a virada do século XIX para 0 século XX. Ao analisar a História dos conjuntos, contida nos livros didáticos aprovados pelo PNLD 
2018 foi possível constatar algumas enunciações relacionados também à valorização da

Matemática. Vejamos as mesmas a seguir, ilustradas nas Figuras de 1 a 6.

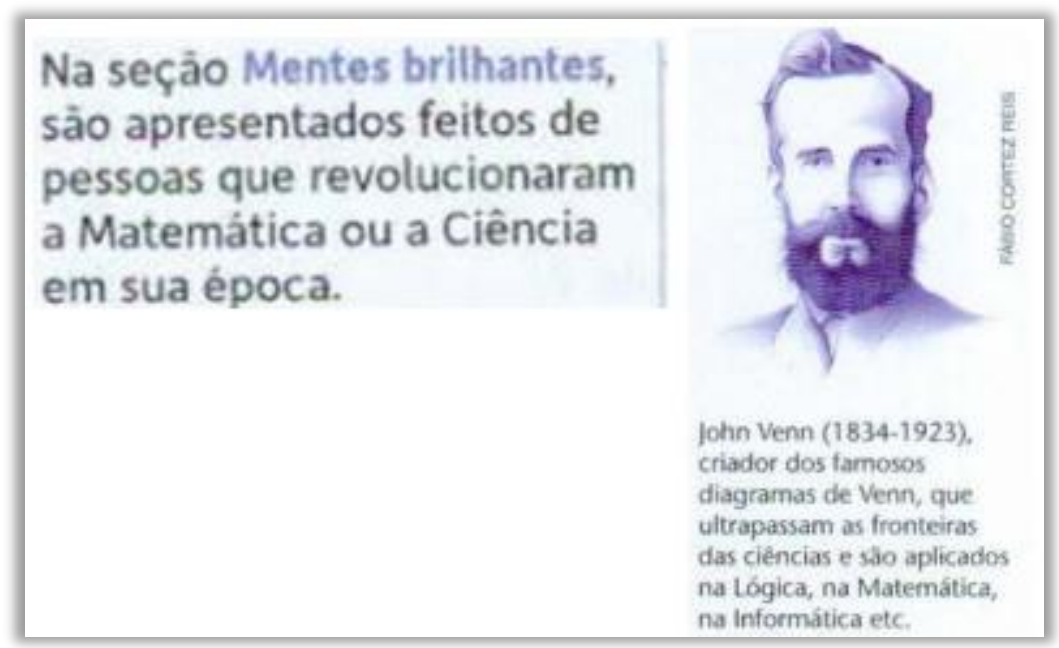

Figura 1: Valorização matemática no contexto da história dos conjuntos (PAIVA, 2017, v. 1, p. 3-9)

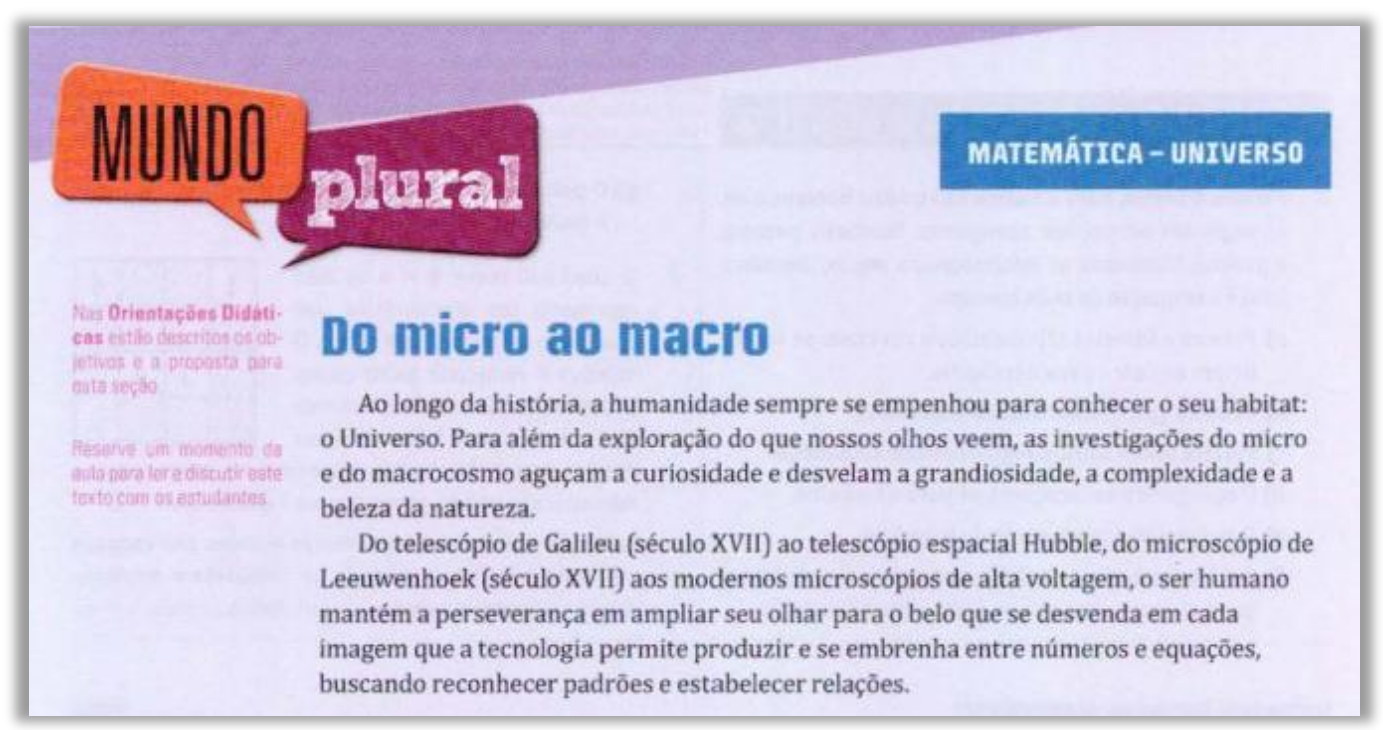

Figura 2: Valorização matemática no contexto da história dos conjuntos (SMOLE e DINIZ, 2017, v. 1, p. 34)

A propriedade transitiva também é conhecida por ser um tipo de silogismo e é constantemente empregada em deduções lógicas. O desenvolvimento do silogismo é atribuído a Aristóteles (384-322 a.C.), um dos grandes pensadores da Grécia Antiga. Atualmente, o silogismo é estudado em diversas áreas do conhecimento, como na Filosofia e no Direito. Nessas deduções, em geral, sāo propostas duas premissas e, por meio do silogismo, obtèm-se uma conclusão.

Figura 3: Valorização matemática no contexto da história dos conjuntos (CHAVANTE e PRESTES, 2016, v. 1, p. 25) 


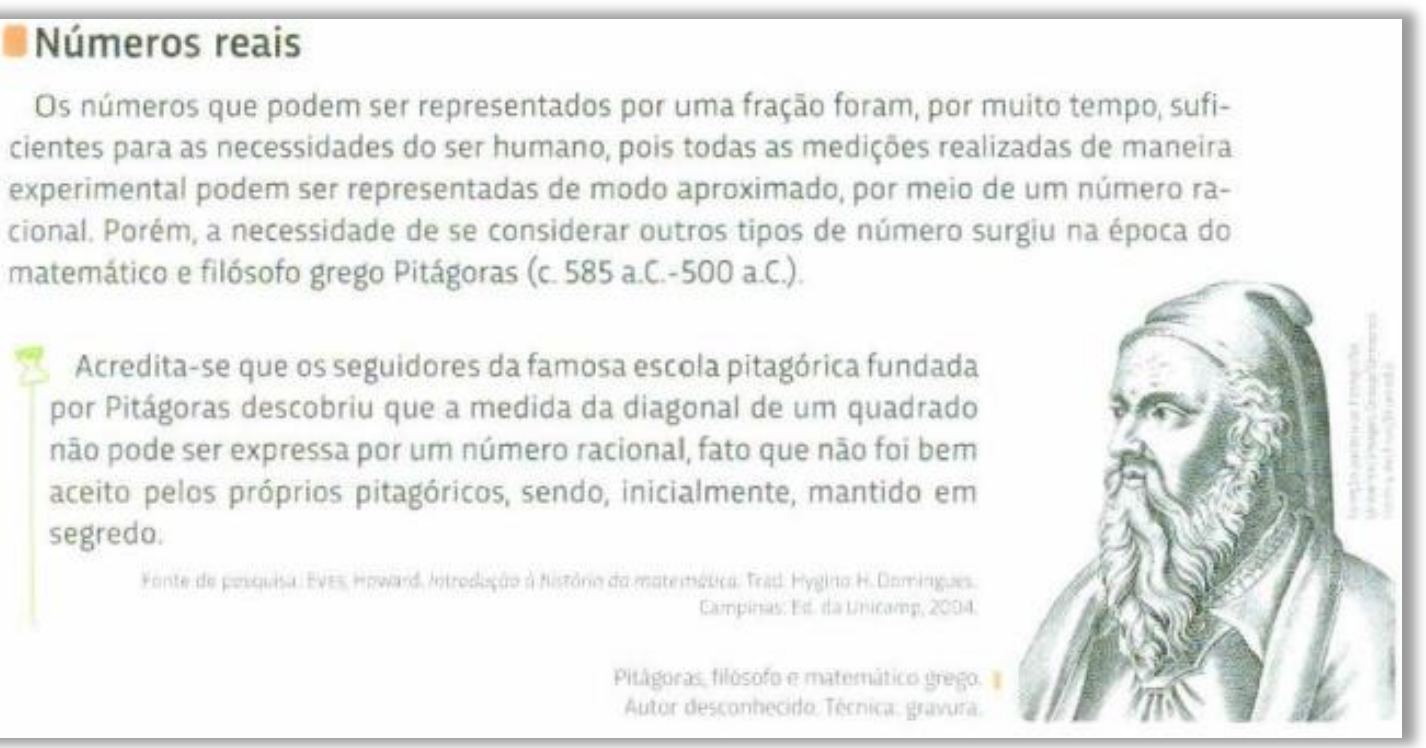

Figura 4: Valorização matemática no contexto da história dos conjuntos (CHAVANTE e PRESTES, 2016, v. 1, p. 13)

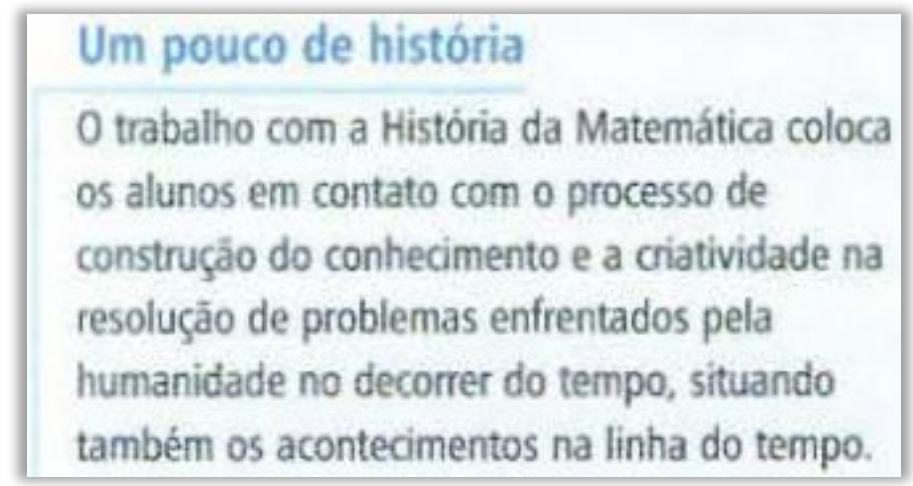

Figura 5: Valorização matemática no contexto da história dos conjuntos (IEZZI et al., 2017, v. 1, p. 4)

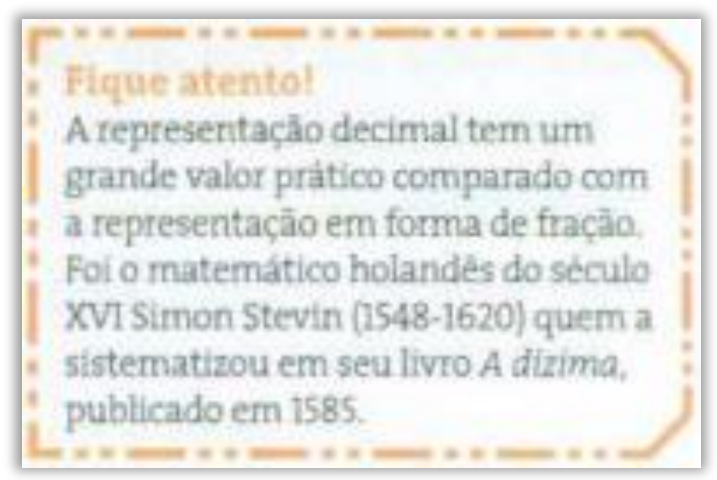

Figura 6: Valorização matemática no contexto da história dos conjuntos (DANTE, 2017, v. 1, p. 17)

As enunciações ilustradas nas Figuras de 1 a 6 buscaram trazer uma abordagem histórica da Matemática, dando a ideia de que as descobertas citadas nessas enunciações são uteis até os dias atuais e com utilidades em campos que vão além da Matemática, tal abordagem da ideia de 
que a Matemática é algo de grande valor para a humanidade, devida às contribuições que a mesma trouxe para o campo científico e outros campos do saber.

Para esse trabalho, o que nos chamou atenção foi que, ao destacar a importância da Matemática, os autores dos livros didáticos buscaram apoiar-se em exemplos que os personagens históricos de destaque eram povos pertencentes à civilização ocidental, ou seja, "o texto curricular conserva, de forma evidente, as marcas da herança colonial" (SILVA, 2015, p. 101-102).

Por meio das enunciações anteriores temos também que, a forma como foi feita a abordagem matemática, buscando valorar seu conhecimento e dando a ela um espaço geográfico de origem, estabeleceu-se uma relação de sabe e poder, creditando a uma certa região e a um determinado povo uma importância grandiosa e uma hegemonia na história. Em consequência disso, fez-se com que outros conhecimentos, outros povos, outras culturas e, entre elas a cultura popular negra, ficassem "apagadas", ou seja, um processo de invisibilidade dos seus feitos.

Outras enunciações presentes nos livros didáticos aprovados no PLND 2018 (BRASIL, 2017) contribuem para esse pensamento acerca de uma hegemonia do povo ocidental, durante a apresentação da história da Matemática. Essa hegemonia também foi observada por D’Ambrosio (1996) ao considerar que,

\footnotetext{
de fato, quando nos referimos à Matemática estamos identificando o conhecimento que se originou nas regiões banhadas pelo Mar Mediterrâneo. Mesmo reconhecendo que outras culturas tiveram influência na evolução dessa forma de conhecimento, sua organização intelectual e social é devida aos povos dessas regiões. Por razões várias, ainda pouco explicadas, a civilização ocidental, que resultou dessas culturas, veio a se impor a todo o planeta. (D'AMBROSIO, 2012, p.338).
}

Essa maneira de apresentar a história da Matemática contribui para que o currículo de Matemática seja visto como um caráter estático, ou seja, inviabiliza que outros modos de vidas também possam ser representados. As enunciações a seguir, Figuras de 7 a 10, contribuíram para nosso pensamento acerca de uma hegemonia no currículo de Matemática.

\section{O sistema de numeração que utilizamos hoje, com dez símbolos, é derivado do} sistema indo-arábico e foi introduzido na Europa no século XIII.

Figura 7: Hegemonia Europeia na história dos conjuntos (PAIVA, 2015, v. 1, p. 8) 


\section{CONECTADO}

Os primeiros registros históricos sobre debates e tentativas de definir o conceito de infinito datam da Antiguidade grega, com os filósofos Zenão de Eleia (cerca de 490 a.C. 430 a.C.), Demócrito (cerca de 460 a.C.-370 a.C.), Aristóteles (384 a.C.-322 a.C.) e Arquimedes (287 a.C.-212 a.C.). Os argumentos mais famosos sobre esses debates sào, sem dúvida, os paradoxos de Zenão, com os quais ele pretendia provar a inconsistência do conceito de infinito (relacionado ao movimento, ao espaço e ao tempo) adotado até então.

Figura 8: Hegemonia Europeia na história dos conjuntos (SMOLE e DINIZ, 2017, v. 1, p. 11)

De uso corrente em Matemática, a noçāo básica de conjunto não é definida, ou seja, é aceita intuitivamente e, por isso, chamada noção primitiva. Ela foi utilizada primeiramente por Georg Cantor (1845-1918), matemático nascido em São Petersburgo, Rússia, mas que passou a maior parte da vida na Alemanha. Segundo Cantor, a noção de conjunto designa uma coleção de objetos bem definidos e discerniveis, chamados elementos do conjunto.

Figura 9: Hegemonia Europeia na história dos conjuntos (IEZZI et al., 2017, v. 1, p. 7)

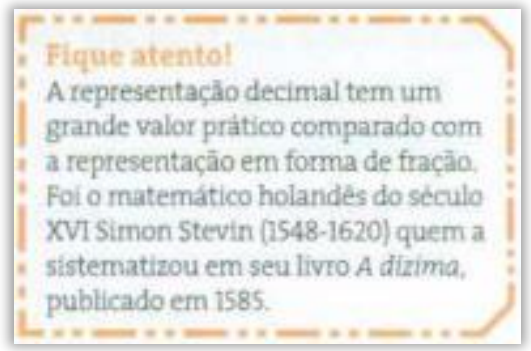

Figura 10: Hegemonia Europeia na história dos conjuntos (DANTE, 2017, v. 1, p. 17)

Nas descrições históricas vistas nas imagens anteriores, foram trazidas algumas informações a respeito de conteúdos matemáticos associados à ideia de conjuntos. Essas informações correspondem a nomes de pessoas ou de povos que introduziram o uso desses conteúdos, o ano em que tal introdução foi feita e a região em que esses povos nasceram ou viveram.

A maneira como os autores apresentam os textos históricos, aparentam que a indicação da região em que os personagens históricos viveram foi tão importante quanto as descobertas trazidas por eles. Com isso, dá-se a ideia de que, o fato de os personagens históricos terem vivido em regiões ocidentais, deram as suas descobertas maior credibilidade. Um exemplo disso, é no caso da Smole e Diniz (2017, p. 11) que buscaram destacar o século em que o sistema indoarábico foi introduzido na Europa, dando a impressão de que era preciso chegar à Europa para que tal sistema pudesse ser reconhecido como importante. As outras enunciações buscaram 
indicar junto à apresentação dos feitos históricos, os respectivos países da região europeia em que tais personagens nasceram e viveram.

A questão de que o crivo europeu valoriza determinado fato, foi algo que observamos em outros momentos da abordagem histórica feita nos livros didáticos ao trabalhem com o conceito de conjuntos. Vejamos a seguir alguns desses momentos - Figuras 11, 12 e 13.

Um dos primeiros estudiosos sobre as proporções humanas foi Marcus Vitruvius Pollio, arquiteto e escritor romano do século $\mathrm{l}$. Esse estudioso alegava que um corpo bem formado devia apresentar proporções harmoniosas. Observe a interpretação que Leonardo da Vinci fez das ideias de Vitruvius, quase quinze séculos mais tarde.

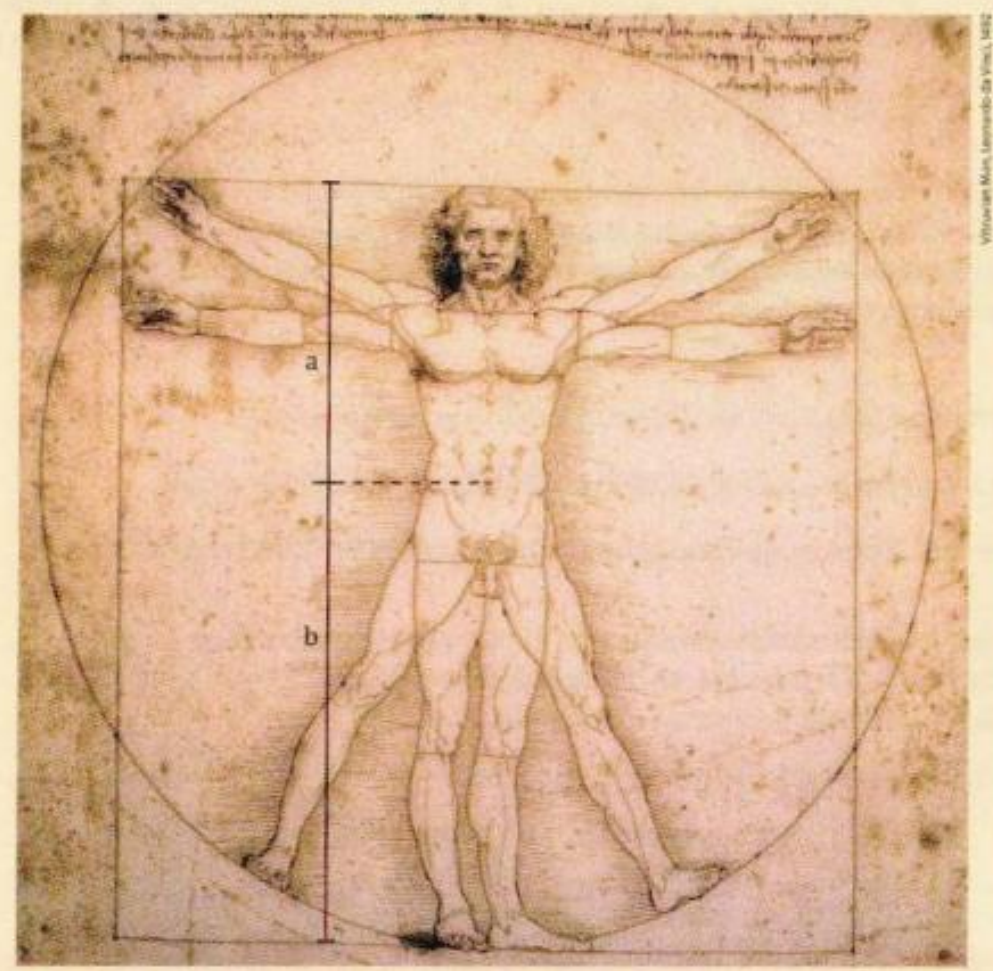

Parte do famoso desenho de Leonardo da Vinci, Homem vitruviano, com destaque para uma das proporçōes áureas no corpo humano; elaborado com caneta, tinta, aquarela e ponta metálica sobre papel, $34,3 \mathrm{~cm} \times 24,5 \mathrm{~cm}$. Gallerie dell' Accademia, Veneza, Italia, 1492.

Figura 11: Relações matemáticas com outros campos do saber (SMOLE e DINIZ, 2017, v. 1, p. 23) 


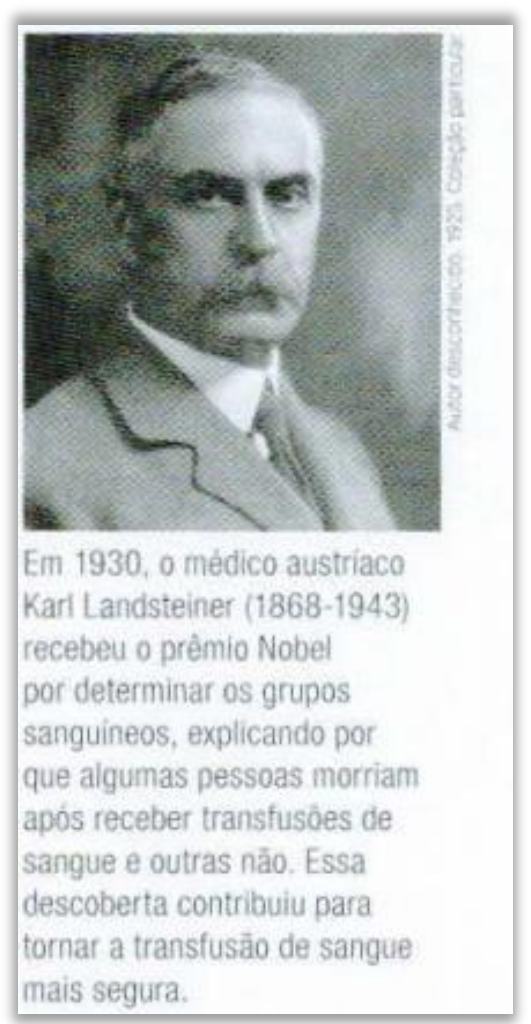

Figura 12: Relações matemáticas com outros campos do saber (CHAVANTE e PRESTES, 2016, v. 1, p. 15)

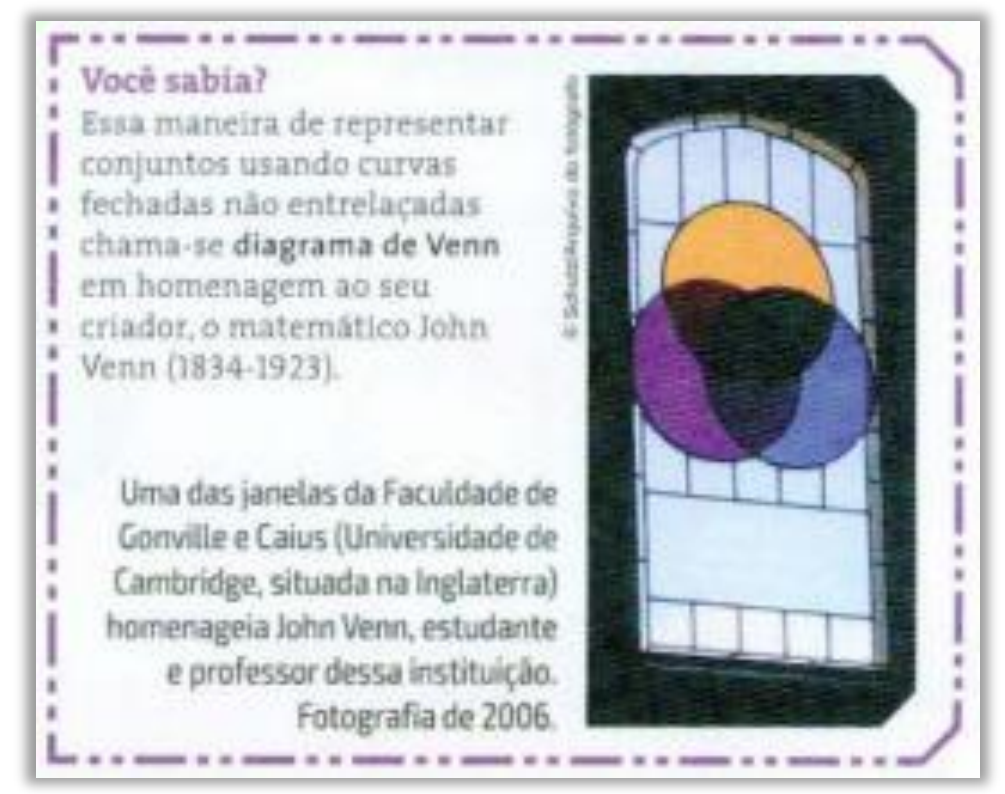

Figura 13: Relações matemáticas com outros campos do saber (DANTE, 2017, v. 1, p. 29)

As enunciações anteriores foram retiradas de um contexto em que os autores buscaram exemplificar o uso, fora do campo matemático, de conteúdos que fazem parte do estudo de conjuntos. 
O que estamos entendendo por meio desses exemplos é que os autores, ao estabelecer relações entre história dos conjuntos com outras áreas do conhecimento como, por exemplo, a arte ou a medicina, também fazem isso apoiados por exemplos de imagens ou de personagens associados à cultura ocidental. Tal fato tem proporcionado à essa cultura, novamente, certa hegemonia, ou seja, por meio desses exemplos e dos enunciados analisados nessa seção, tivemos em diferentes momentos e em diferentes abordagens certa regularidade em relação à hegemonização da cultura ocidental e um apagamento de discussões que pudessem dar visibilidade a cultura popular negra.

As enunciações apresentadas até agora podem ser vistas como um alinhamento de ideias a respeito da importância da Matemática, de como foi dada sua construção histórica e de como essa disciplina possui relações com outros tipos de conhecimento. Todas essas enunciações indicaram como fator regular o fato de estarem associadas à uma cultura ocidental, cuja história não está associada à cultura popular negra.

O que estamos questionando ao indicar a hegemonia citada, não é uma simples mudança em que a cultura popular negra possa ser dada como a protagonista, mas uma desconstrução dessa representação para criar possibilidades outras, de outras culturas e outras diferenças. Entendemos que apesar de algumas conquistas a respeito dos negros já terem sido alcançadas, "[...] ainda existem limites marcados de sua representação e participação nos centros de poder cultural [...]" (HALL, 2016, p. 228). Sendo assim, tomando o currículo como um campo político e discursivo, entendemos que o mesmo seja de grande importância para a nossa luta e que por meio dele seja possível

questionar também as formas mais sutis de essencialismo, como aquela que se manifesta através do essencialismo cultural. Embora não reduza a identidade étnica e racial a seus aspectos biológicos, o essencialismo cultural concebe a identidade simplesmente como a expressão de alguma propriedade cultural intrínseca dos diferentes grupos étnicos e raciais. Nessa concepção a identidade, embora cultural, é vista como fixa e absoluta. (SILVA, 2015, p. 104).

Dessa maneira, podemos concluir que o currículo de Matemática, ao apresentar esse tipo de representação, cria processos que endereçam um tipo de identidade e hegemonizam de maneira discursivamente como deve ser apresentada a história da Matemática. O que gostaríamos de evidenciar é a necessidade de um currículo baseado na multiplicidade e na diferença, que possa quebrar com esses discursos hegemônicos. 


\section{Considerações}

Esse artigo teve por objetivo descrever e analisar discursos mobilizados na abordagem feita acerca da História dos Conjuntos contidas nos livros didáticos do Ensino Médio aprovados no PLND 2018 (BRASIL, 2017). Observamos, nas análises, que o currículo de Matemática, enquanto campo político, ao apresentar determinadas representações sobre a história da Matemática, provoca o apagamento de questões étnicos-raciais, principalmente as questões relacionadas à cultura popular negra, enquanto hegemoniza uma cultura ocidental por meios de seus feitos históricos, em contexto científicos e áreas afins.

Ao evidenciar tal fato, não queremos somente a inclusão de tal cultura, mas gostaríamos que tais fatos fossem repensados, que o currículo de Matemática e sua abordagem da história da Matemática fosse vista pela multiplicidade, em que o currículo de Matemática crie espaços de possibilidades para pensar em outros feitos, buscando escapar do eurocentrismo.

\section{Referências}

BRASIL. Ministério da Educação. Secretaria de Educação Básica. PNLD 2018: Matemática - Guia de Livros Didáticos: Ensino Médio. Brasília: MEC/SEB, 2017.

CHAVANTE. Eduardo; PRESTES, Diego. Quadrante Matemática - Ensino Médio. v. 1. São Paulo. Edições SM, 2016.

CORADETTI, Camila Aparecida Lopes Manoel; SILVA, Marcio Antonio da. Famílias felizes e saudáveis! Livros didáticos de Matemática e a produção de sujeitos. Reflexão e Ação, Santa Cruz do Sul, v. 26, n. 1, p. 219-235, jan./abr. 2018.

D’AMBROSIO, Ubiratan. Tendências e perspectivas historiográficas e novos desafios na História da Matemática e na Educação Matemática. Educação Matemática Pesquisa, São Paulo, v. 14, n. 3, p. 336-347, 2012.

DANTE, Luiz Roberto. Matemática: contexto e aplicações. v. 1, 2. ed. São Paulo: Ática, 2013.

FISCHER, Rosa Maria Bueno. Trabalhar com Foucault: a arqueologia de uma paixão. Belo Horizonte: Autêntica Editora, 2012.

FOUCAULT, Michael. A arqueologia do saber. Tradução de Luiz Felipe Baeta Neves. 3. ed. Rio de Janeiro: Forense-Universitária, 1987.

HALL, Stuart. Cultura e representação. Rio de Janeiro: EdPUC-Rio, Apicuri, 2016.

HALL, Stuart. Da diáspora: identidades e mediações culturais. Belo Horizonte: EdUFMG, 2003. 
IEZZI, Gelson; DOLCE, Osvaldo; DEGENSZAJN, David; PÉRIGO, Roberto; ALMEIDA, Nilze de. Matemática: ciência e aplicações. v. 1, 7. ed. São Paulo: Saraiva, 2010.

LOPES, Alice Cassimiro; MACEDO, Elizabete. Teorias de Currículo. São Paulo: Cortez, 2011.

MANOEL, Alan Pereira. Aspectos históricos do estudo do Cálculo Diferencial e Integral no ensino secundário brasileiro entre 1889 e 1929. 2018. 234f. Dissertação (Mestrado em Educação Matemática) - Instituto de Matemática. Universidade Federal de Mato Grosso do Sul. Campo Grande.

PAIVA, Manoel. Matemática. v. 1, 2. ed. São Paulo: Moderna, 2017.

SILVA. Tomaz Tadeu da. Documentos de identidade: uma introdução às teorias do currículo. Belo Horizonte: Autêntica, 2015.

SMOLE, Katia Stocco; DINIZ, Maria Ignez. Matemática: Ensino Médio. v. 1, 8. ed. São Paulo: Saraiva, 2017.

VALENTE, Wagner Rodrigues. A disciplina Matemática: etapas históricas de um saber escolar no Brasil. In: OLIVEIRA, Marcus Aurelio Taborda de; RANZI, Serlei Maria Fischer. (Org). História das disciplinas escolares no Brasil: contribuições para o debate. Bragança Paulista: EdUSF, 2003, p. 217-254. 